\title{
REFERÉNDUM LEGISLATIVO $Y$ CONSTITUCIONAL EN EL URUGUAY
}

\author{
Miguel Angel Semino
}

El derecho constitucional uruguayo consagra diversos institutos de la denominada -con mayor o menor felicidad y aciertondemocracia directa 0 ugobierno directo*. Estos son los siguientes:

1) refereindum contra las leyes;

2) referéndum contra los decretos (ordenanzas) municipales;

3) referendum de ratificación constitucional (tambièn llamado oplebiscito), y aqui aprovecho para señalar que, en nuestro derecho constitucional, no existen diferencias conceptuales válidas entre ambos institutos:

4) iniciativa popular legislativa;

5) iniciativa popular municipal y

6) iniciativa popular constitucional.

De acuerdo al programa establecido, me tocará ocuparme del referéndum contra las leyes y del referéndum de ratificación constitucional, exclusivamente. Aún asi, y por obvias razones de tiempo disponible sólo podré comentar parcialmente algunos aspectos de los mencionados institutos: los que, en mi opinión, estimo que puedan resultar más interesantes y fundamentales para un publico extranjero. 
II

Comenzaré citando las disposiciones constitucionales que regulan el referéndum legislativo, que es el primero que tratare. El articulo 82 reza: "La Nación adopta para su gobierno la forma democratica republicana. Su soberania será ejercida directamente por el Cuerpo Electoral en los casos de elección. iniciativa y referéndum e indirectamente por los poderes representativos que establece esta Consttución; todo conforme a las reglas expresadas en la mismav.

A su vez, el inciso segundo del articulo 79 dispone: "El veinticinco por ciento del total de inscritos habilitados para votar, podra interponer, dentro del año de su promulgación, el recurso de referóndum contra las leyes y ejercer el derecho de iniciativa anta el Poder Legislativo. Estos institutos no son aplicables con respecto a las leyes que establezcan tributos. Tampoco caben en los casces en que la iniciativa sea privativa del Poder Ejecutivo. Ambos institutos serán reglamentados por ley, dictada por mayoria absoluta del total de componentes de cada Cámaraw.

\section{III}

Analizando nuestro texto constitucional podemos, desde ya, sehalar algunos rasgos especificos del instifuto:

1) Es un instrumento para que la Nación ejerza directamente su soberania a través del Cuerpo Electoral. En otras palabras, es un derecho, una potestad de la ciudadania y no de las autoridades. Además, es un -recurson, es decir, un instrumento para impugnar o cuestionar una ley vigente.

2) Es de carácter preceptivo, vale decir que sus efectos son vinculantes u obligatorios. Se cpone asi al de carácter consultivo -que es una suerte de oncuesta oficial de opinión pública-previsto, por ejemplo, en la Constitución española (articulo 92).

3) Con dos únicas excepciones todas las leyes pueden ser sometidas a referondum. La ptimera excepción apunta a las nomas de naturaleza tributaria, por razones fácilmente comprensibles. La segunda requiere una breve explicación: en nuestro derecho son leyes cuya iniciativa privativa pertenece al Poder Ejecutivo: las de presupuesto, las que conceden exoneraciones tributarias y fijan salarios minimos, las que crean empleos y establecen causales y aumento jubilatorios $y$, por último, las doclaradas rde urgente consideración - para su trímite parlamentario.

4) Ninguno de los que la Constitución califica de Poderes representativos (Ejecutivo, Legislativo y Judicial) esta juridicamente habilitado para convocar un referéndum legistativo. Solamente puede hacerlo el Cuerpo Electoral cumpliendo dos requisitos ineludibles y que reiterasemos de inmediato.

5) El primer requisto es de crden numerico - cuantitativo: el $25 \%$ de los inscritos en et Registro Electoral (en el momento actual alrededor de 600.000 ciudadanos) debe de manifestar fehacientemente su voluntad de interponer el recurso de referèndum contra determinada ley en su totalidad o contra algunos de sus artículos. El segundo requisito es de orden temporal: el recurso habrá de ser deducido dentro del año calendario que empieza a correr al dia siguiente de ta promulgación de la ley cuestionada. Si asi no se procede el paso inexorable del tiempo producirá la caducidad del derecho. 
6) El control de la regularidad juridica formal y substancial- del referéndum, como, por lo demás, de todos los actos y procedimientos electorales, está a cargo de un tribunal que, entre nosotros, se denomina wCorte Electoral- (articulos 322 a 328 de la Constitución) y que es garantia de competencia técnica y de imparcialidad politica. No en balde, en reciente encuesta sobre la credibilidad de sus eleccionos realizada en doce paises latinoamericanos, el mío era -do lejos- el que más confianza tenia en las mismas.

\section{IV}

Deliberadamente, en esta rápida caracterización que estoy haciendo de nuestro referéndum legislativo, he dejado hasta el momento de lado toda mención acerca de sil es constitutivo, derogatorio o anulatorio. Lo he hecho porque este es un tema altamente polémico - al menos en mi pais - y de enormes consecuencias fácticas. Por ello, me permito creer que vale la pena hacer un capitulo aparte con ol tema para señalar, brevemente, cómo se plante $\delta$ en el Uruguay e problema suscitado por la ley No. 15849 del 22 de diciembre de 1986 que, en la práctica, consagró una amnistia para los militares y policias presuntamente responsables de violaciones a los derechos humanos durante el gobiemo *de tacto-. Esta ley fue impugnada de acuerdo al texto constifucional antes citado.

1) El reterendum legisiativo en mi pais carece de naturaleza constitutiva sobre la ley: es un simple recurso contra ella. Aparte del tenor literal del texto, cabe recordar que nuestro sistema de gobierno es, esencialmente -representativo*, aunque admite institutos propios del gobiemo *directo- (lo que to transforma en "semirrepresen- tativon), EI pueblo no ejerce, en principio, la función legislativa. las leyes adquieren total vigencia se perleccionan - no bien scon promulgadas según to dispone la Constitución (Sección VII). Al mismo tiempo que entran en vigencia comienzan a producir efectos jurídicos legitimos. Por el contrario, en el sistema suizo la tunción legislativa es compartid entre el Parlamento y el pueblo. Ninguna ley federal aprobada por el Poder Legislativo adquiere vigencia y produce efectos si no ha recibido la aprobación expresa o tácita dol Cuerpo Electoral (articulo 89 de la Constitución suiza). La aprobación expresa ocurre cuando se convoca a referéndum y el pueblo vota afirmativamente. Hay aprobación tácita cuando vence el plazo establecido y los interesados (ciudadanos o cantones) no han solicitado la consulta popular.

2) Resulta de toda evidencia que los efectos de una votación negativa no pueden ser los mismos en el sistema uruguayo (semirepresentativo) y en el suizo (semidirecto). En este ultimo una votación negativa implica que la ley en (en realidad, "proyecto de leys) se considera inexistente, nula, no nacida, En el caso unguaryo, la votación negativa fulmina una norma plenamente vigente y que está produciendo efectos desde su promulgacion. Sobre esto no cabe la menor duda. Ahora bien ¿qué alcance tene la mencionada votación negativa sobre esa ley vigente? ¿la deroga (hacia ef futuro) o la anula (hacia el pasado)?. Es éste el "quid" del asunto que ha merecido una erudita $y$ apasionada discusión en la cátedra, la prensa y el Parlamento. Puedo dar fe de mis afirmaciones porque las circuns- tancias quisieron que tuviera que encabezar la batalla juridica a favor de la constitucionalidad de la ley No. 15848 (bataila ganada) y del efecto 
derogatorio del referéndum negativo (batalla por ganarse), Digo que esta última fodavia no se ganó porque el referéndum del 16 de abril de 1989 el pueblo confirmó ta ley de amnistia y, entonces, la discusión académica ya no tenía sentido. Pero ¿qué hubiera pasado si el resultado del referéndum hubiese sido dilerente?

3) En forma harto sintética plantearé algunos de los argumentos que me llevan a sostener el efecto derogatorio de un reteréndum no confirmativo. Para los interesados en un estudio másprofundo de este problema susceptible de presentarse en cualquier pais donde la Constitución no aclaro cuáles son las consecuencias de la aplicación del referéndum -me permito recomendar la lectura del libro publicado por el Centro de Asesoria y Promoción Electoral (CAPEL) del Instituto Interamericano de Derechos humanos y que se titula: =El referéndum uruguayo del 16 de abril de 1989 . Remitiendome a esa lectura como complemento, mis razones son, básicamente, las siguientes:

a) La stuación que se deriva de la abrogación de una ley a causa del resultado de un referéndum es esencialmente similar a la ofrecida cuando una ley posterior deroga a una anterior:

b) El principio general en materia de derogacion de leyes establece que la derogación supone la extinción, para el futuro, de la ley anterior,

c) Esta posición es la única respetuosa de los legitimos derechos adquiridos durante la vigencia de la ley derogada (digamos a título de ejemplo: la ley derogada estableció una nueva causal de divorcio y hube gente que discolvió su vinculo corryugal y contrajo nuevo matrimonio, del que nacieron hijos. Electuado el referéndum lios nuevamente. casados se comvierten en bigamos?. ¿sus hijos se vuelven ilegitimos? del matrimonio disuelto renace? etc.);

d) En nuestro derecho el fallo do la Suprema Corte que declara la inconstitucionalidad de una ley se aplica exclusivamente al caso de autos: la ley no se deroga ni se anula. Si en un caso tan grave como el de la inconstitucionalidad la ley queda vigente, salvo para los sujetos procesales, no es lógico sostener que una impugnaciòn mediante referéndum finalice con la anulación de la ley -..ex tuncis -máxime cuando el recurso puede interponerse también por razones de oportunidad o conveniencia (es decit, razones no juridicas).

4) La loy que reglamentó el reteréndum legislativo (de 20 de cnero de 1989) no se pronuncio sobre el punto que estoy exponiendo. Las pasiones politicas estaban muy agitadas, no pudo llegarse a un consenso y no so quiso resolver el tema por simple votación mayoritaria. Pero ya hemos tenido otro reteréndum (este si con resultado desaprobatorio) en diciembre del anto pasado y se divisan mas en el horizonte politico nacional. Inexorablemente, habrá que establecer con claridad que - como lo indica la lógica juridica, el sentido comán y la equidad - el efecto de un referéndum legislativo no aprobatorio es solamente $\approx e x$ nunc", para el futuro (derogatorio y no anulatorio).

\section{v}

Comentaré ahora - en forma muy genórica el reloréndum de ratificación constitucionai instituido por el articulo 331 de nuestra Carta, que también es denominado por ella "plebiscito", Este método de aprobación de una fefoma, total o parcial, de la Constiución 
aparece entre nosotros con la ley del 28 de agosto de 1912 y es aplicado en la práctica por primera vez el 25 de noviembre de 1917 . en cuya fecha la ciudadania dio su consentimiento a nuestra segunda Constitución, vigonte a partir de 1918.

De acuerdo al derecho positivo uruguayo hay cuatro procedimientos para reformar la =lex fundamentalis". Los sintetizo a continusción:

a) por iniciativa popular $(10 \%$ de los ciudadanos presenta un proyecto articulado. El Parlamento, a su vez, podrá formular proyectos substitutivos):

b) por iniciativa parlamentaria de $2 / 5$ de la Asamblea General (reunión conjunta de las dos cámaras):

c) por docisión de una Convención Nacional Constituyente que debe pronunciarse sobre proyectos presentados por los legisladorss, el Poder Ejecutivo a sus propios miembros. Pueden aprobarse varios proyectos de reforma o uno solo;

d) por iniciativa pariamentaria (aleyes constitucionalesn) aprobadas por $2 / 3$ dol total de componentes de cada cámara por separado.

En todos los casos releridos habrá que convocar a una consulta popular para que la ciudadania pronuncie su última -y definitivapalabra ¿Por qué? Simplemente, porque asi Io manda la Constitución: Podria no mandarlo, como no lo mandaba nuestra primera Carta (la de 1830) y tantas otras que rigen o han regido en este mundo.

Quiero significar con esto que el requisito de ratificación mediante un referéndum o plebiscito - de carácter obviamente constitutivo, en este caso - no es dogma ticamente necesario desde el ángulo del principismo democratico y de la comveriencia politica, que son conceptos atines con ell de legitimidad y no con el de legalidad formal.

De cualquier modo, en su concreción práctica, el referéndum implica una votación (por "Sin o por "Non) sobre un proyecto orgánico de reforma constitucional, total o parcial. Puede ocurrir - y asi consta en nuestros anales electorales-que se somotan a juicio de la ciudadania varios proyectos reformistas (por ejemplo, en 1966). Esto puede dificultar que se obtenga una clara mayoria a favor de unos $u$ otros - que quizís difieran en pocos temas-, pero la solución ai problema es de indole politica y no juridica.

\section{VI}

Por último y para terminar, creo del caso formular un juicio valorativo sobre nuestro sistema de democracia semirepresentativa, que encuentra en el referéndum su prenda más notable. La modalidad de aprobación constitucional es la que cuenta con una opinión sin duda unánime a su favor. La misma está avalada por una ya larga práctica, por haber contribuido de manera decisiva a precipitar el fin de la dicladura castrense que ensombreció una centenaria tradición de gobiernos civiles y por su contenido de innegable autenticidad democratica: la Nacion es titular de la soberania y sujeto del poder constituyente (articulo 4, 82 y 331 de la Constitución).

Respecto al referéndum legislativo $\mathrm{mi}$ opinión es también positiva, pero requiere algunas puntualizaciones que siempre realizo: Nuestro régimen de goblemo - ya to dije - es esencialmente del tipo "representativo", con agregados de democracia directa - el referéndum, por ejemplo - por lo que cabe tambien clasificarlo como 
«gemirepresentativo*. Pero aún asi. subasamento doctrinario es diferente del que sustenta al llamado gobiemo «directo*, suponienda que este tipo exista o haya existido en forma pura a lo largo de la historia (que no es asi). Por tanto no estimo conveniente ni prudente que las leyes, particularmente en asuntos altamente especializados, se vean fácilmente expuestas a una posible derogación utilizando el referéndum por motivos a veces estrictamente partidistas o demagógicos. Por ejemplo, cuando el Parlamento de mi pais, en la primera decada de este siglo, aprobó la ley de divarcio o la abolición de la ensefianza religiosa en las escuelas estatales, quizás hublese visto su obra demolida por un referendum popular, de haberlo habido en esa época. $Y$, ante la historia ¿quién hubiora tenido razon..?

En definitiva. Estoy por conservar el releréndum - limitando a seis meses el plazo de caducidad - pero no por extender su radio de acción ni por disminuir el porcentaje de voluntades requeridas (25\% del Cuerpo Electoral) pars interponerto: una excesiva facilidad de convocatoria podrla desvirtuar su legitima filiación democratica y transfomnarlo en un instrumento de agitación politica y de desestabilización institucional.

\section{ANEXO}

Constitución de la Repuiblica Oriental del unuguay

AATICULO 331. La presente Constitución podira ser reformada, total o parcialmente, conforme a los siguientes procedimientos:

A) Por iniclativa del diez por ciento de los ciudadanos inseritos en el Registro Cívico
Nacional, presentando un proyecto articulado que se elevará al Presidente de la Asamblea General, deblendo ser sometido a la decision popular en la elección más inmediata.

La Asamblea General, en reunión de ambas Camaras, podrá formular proyectos sustitutivos que someterá a la decisión plebiscitaria, juntamente con la iniciativa populat.

B) Por proyectos de reforma que reúnan dos quintos del total de componentes de la Asamblea General presentados al Presidente de la misma, los que serán sometidos al plebiscito en la primera elección que se realice.

Para que el plebiscito sea alimativo en los casos de los incisos A) y B), se requerira que vote por "Sio la mayoria absoluta de los ciudadanos que concurran a los comicios, la que debe representar por lo menos, el treinta y cinco por clento del total de inscritos en el Registro Civico Nacional.

C) Los Senadores, los Representantes y el Poder Ejocutivo podrán presentar proyectos de reforma que deberán ser aprobados por mayoria absoluta del total de los componentes de la Asamblea General.

El proyecto que fuere desechado no podrá reiterarse hasta el siguiente periodo legislativo, debiendo observar las mismas formalidades.

Aprobada la iniclativa y promulgada por el Presidente de ta Asamblea Genoral, el Poder Ejecutivo convocará, dentro de los noventa dís siguientes, a elecciones de una Convención Nacional Constituyente que deliberara y resolvera sobre las iniciativas aprobadas para la reforma, ast como sobre 
las demás que puedan presentarse ante la Convención.

El nùmero de convencionales será doble del de Legisladores. Conjuntamente se elegirán suplentes en número doble al de convencionales. Las condiciones de elegibilidad, inmunidades e incompatibilidades, serán las que rijan para los Representantes.

Su elección por listas departamentales, se regirá por el sistema de la representación proporcional integral y conforme a las leyes vigentes para la elección de Representantes. La Convención se reunirá dentro del plazo de un año, contado desde la techa en que se haya promulgado la iniciativa de reforma.

Las resoluciones de la Convención deberàn tomarse por mayoria absoluta del nùmero total de convencionales, debiendo terminar sus tareas dentro del año, contado desde la techa de su instalación. El proyecto o proyectos redactados por la Convención serán comunicados al Poder Ejecutivo para su inmediata y profusa publicación.

El proyecto o proyectos redactados por la Convención deberán ser ratificados por el Cuerpo Electoral, convocado al efecto por el Poder Elecutivo, en la focha que indicará la Convención Nacional Constituyente.

Los votantes se expresardin por *Si= o por -No- y si fueran varios los textos de enmienda, se pronunciarán por separado sobre cada uno de ellos. A tal efecto, la Convención Constituyente agrupará las reformas que por su naturaleza exijan pronunciamiento de conjunto. Un tercio de miembros de la Convención podrá exigir et pronunciamiento de conjunto. Un tercio de miembros de la Convención podra exigir el pronunciamiento por separado de uno o varios textos. La reforma o reformas deberán ser aprobadas por mayoria de sufragios, que no sera inferior al treinta y cinco por ciento de los ciudadanos inscritos en el Pegistro Civico Nacional:

En los casos de los aportados A) y B) sólo se someterản a la ratificación plebiscitaria simultánea a las más próximas elecciones, los proyectos que hubieren sido presentados con seis meses de anticipación - por lo menos - a la techa de aquéllas, 0 con tres meses para las formulas sustitutivas que aprobaré la Asamblea General en el primero de dicho caso.

Los presentados después de tales términos, se scmeteran al plebiscito conjuntamente con las elecciones subsiguientes.

D) La Constitución podra ser reformada, también, por leyes constitucionales que requerirán para su sanción, los dos tercios del total de componentes de cada una de las Camaras dentro de una misma Legislatura. Las leyes constitucionales no podrán ser vetadas por el Poder Ejecutivo y entrarán en vigencia luego que el electorado convocado especialmente en la fecha que la misma ley determine, exprese su conformidad por mayoria absoluta de los votos emitidos y serán promulgadas por el Presidente de la Asamblea General.

E) Si la conwocatoria del Cuerpo Electoral para la ratificacibn de las enmiendas, en los casos de los apartados A), B), C) y D) coincidiera con alguna elección de integrantes de órganos del Estado, los ciudadanos deberán expresar su voluntad sobre las reformas constitucionales, en documentos separados y con independencia de las tistas de elecoibn. Cuando las retormas se refieran a ta elección de cargos electivos. 
al ser sometidas al plebiscito, simultáneamente se votará para escos cargos por el sistema propuesto y por el anterior, teniendo fuerza imperativa la decisión plebiscitaria. 